See Article page e65.

\section{Commentary: New era, old challenge}

\author{
Jian-Yong Ding, MD, PhD
}

Since 1983, lung transplantation has become a standard treatment option for end-stage lung disease. It is still hampered by some persistent obstacles, however, including severe primary graft dysfunction early after transplantation, which is thought to primarily contributed to ischemiareperfusion (IR) injury. ${ }^{1}$ IR injury related to lung transplantation is therefore an old challenge from the start.

To ameliorate the IR injury, donor lung preservation is critical. In fact, the strategy for donor lung preservation has evolved significantly. Even for ideal donors after brain death, however, this preservation time is typically kept to less than 6 hours. On the one hand, there is a shortage of donor lungs around the world; On the other hand, only $20 \%$ of the donors meet the requirements. Ex vivo lung perfusion (EVLP) was brought into being ${ }^{2}$ to extend the donor pool and improve donor quality. For lung transplantation, the application of EVLP is opening a new and exciting era.

Whatever the donor type is, IR plays a critical role in the pathogenesis of primary graft dysfunction. Because donations for which normothermic EVLP is used tend to have worse donor quality and longer durations, the inflammation will undoubtedly be more severe. One article has indicated that inflammatory profiling differs between warm and cold ischemic donor lungs. ${ }^{3}$ With more use of EVLP, there is an urgent need to develop new ways to manage IR during reperfusion.

The article by Burki and colleagues ${ }^{4}$ in this issue of the Journal entitled "Impact of Triptolide During Ex Vivo Lung Perfusion on Grafts After Transplantation in a Rat Model" casts a new sight on this issue. It is a smart design in that triptolide is a water-soluble form with small molecule, which may maximize the impact. As we all know, the anti-inflammatory effects of triptolide have been well documented; however, the precise mechanism is not clear. As to this article, Burki and colleagues ${ }^{4}$ first

\footnotetext{
From the Department of Thoracic Surgery, Zhongshan Hospital, Fudan University, Shanghai, China.

Disclosures: Author has nothing to disclose with regard to commercial support.

Received for publication Feb 2, 2020; accepted for publication Feb 3, 2020; available ahead of print Feb 14, 2020.

Address for reprints: Jian-Yong Ding, MD, PhD, Department of Thoracic Surgery,

Zhongshan Hospital, Fudan University, 180 Fenglin Rd, Shanghai, China (E-mail: ding.jianyong@zs-hospital.sh.cn).

J Thorac Cardiovasc Surg 2021;161:e77

$0022-5223 / \$ 36.00$

Copyright (c) 2020 by The American Association for Thoracic Surgery

https://doi.org/10.1016/j.jtcvs.2020.02.031
}

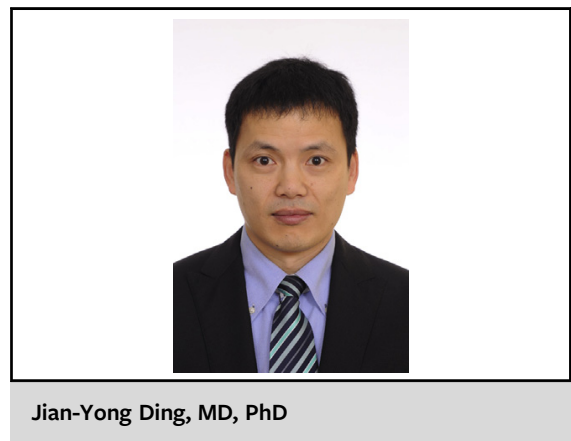

CENTRAL MESSAGE

Introduction of triptolide into graft ex vivo lung perfusion is reasonable and wise for lung transplantation.

used triptolide as a preconditioning agent and found that 4 hours of graft EVLP treatment with triptolide contributed to improved lung graft quality, with attenuated tissue inflammation. Moreover, these favorable effects were sustained, resulting in superior posttransplant graft function and quality. It appears that introducing triptolide into graft EVLP is reasonable and wise.

There are still some limitations. As mentioned in this article, ${ }^{1}$ the precise mechanism of anti-inflammatory effects has not been clearly elucidated. The study demonstrated that triptolide reduced anaerobic metabolism and oxidative stress in lung grafts during EVLP, but it is more of a hypothesis; we do not even know exactly whether the drug directly enters cells or affects cell functions through membrane receptors and second messengers. And too many factors could affect the results of IR injury on lung transplantation, introducing difficulties in balancing between the experiment and control groups. The number is small, and it is also a preliminary study on rodent model, which also means that we should carefully interpret the results.

We should look forward to seeing further studies of triptolide in human lung transplantation, and also attempts with other anti-inflammatory drugs. It does not matter whether the cat is black or white, as long as it catches mice.

\section{References}

1. Van Raemdonck D. Thoracic organs: current preservation technology and future prospects; part 1: lung. Curr Opin Organ Transplant. 2010;15:150-5.

2. Loor G. EVLP: ready for prime time? Semin Thorac Cardiovasc Surg. 2019;31:1-6.

3. Iskender I, Cypel M, Martinu T, Chen M, Sakamoto J, Kim H, et al. Effects of warm versus cold ischemic donor lung preservation on the underlying mechanisms of injuries during ischemia and reperfusion. Transplantation. 2018;102:760-8.

4. Burki S, Noda K, Philips BJ, Velayutham M, Shiva S, Sanchez PG, et al. Impact of triptolide during ex vivo lung perfusion on grafts after transplantation in a rat model. J Thorac Cardiovasc Surg. 2021;161:e65-74. 